\title{
Analysis of Bank Soundness with RGEC Method (Risk Profile, Good Corporate Governance, Income and Capital)
}

\author{
$1^{\text {st }}$ Ahmad Farhan ${ }^{1}, 2^{\text {nd }}$ Safira $^{2}$ \\ Afarhan40@yahoo.com ${ }^{1}$, safira.almunawar@mercubuana.ac.id ${ }^{2}$ \\ Universitas Mercu Buana, Indonesia
}

\begin{abstract}
Abstrak, Isu kondisi Bank Muamalat Indonesia sedang mengalami kendala sudah menjadi pemberitaan beberapa waktu di tahun 2018 ini , hal ini akan berdampak kepada para deposan Bank Mualamat. Bank Muamalat Indonesia merupakan ikon bank syariah di Indonesia. Penelitian ini bertujuan untuk melihat kesehatan Bank Muamalat yang diukur dengan metode RGEC (Risk Profile, Good Corporate Governance, Earnings, and Capital) (1) dengan menggunakan beberapa pengukuran rasio keuangan. Data yang digunakan adalah data dokumentasi dari ikhtisar keuangan tahun 2015 - 2017 hal ini karena saat dilakukan penelitian data yang tersedia baru sampai tahun 2017 dan isu sudah diberitakan sejak tahun 2015. Jenis penelitian ini adalah penelitian deskriptif. Penelitian ini menginformasikan hasil bahwa pada pengukuran profil resiko yang dikur dengan NPF dan FDR menggambarkan pengelolaan risiko telah dilaksanakan dengan baik selanjutnya pada pengukuran tata kelola perusahaan yang diukur dari GCG, Bank Muamalat Indonesia juga sudah menerapkan tata kelola perusahaan secara baik. Aspek Earnings yang penilaiannya dengan mengukur ROA, ROE, NOM, dan BOPO hasilnya dinilai kurang baik namun masih ada usaha-usaha perbaikan di setiap tahunnya oleh Bank Muamalat Indonesia terlihat dari angka rasio tersebut setiap tahunnya selama tahun penelitian ada perbaikan yang signifikan. Aspek permodalan Bank Muamalat Indonesia yang diukur dengan rasio CAR secara keseluruhan mendapat kategori baik.
\end{abstract}

Kata Kunci : Tingkat kesehatan bank, Bank Muamalat,Metode RGEC

\section{Pendahuluan}

Fenomena penelitian ini adalah isu kondisi ketidakstabilan Bank Muamalat Indonesia bahkan pada tahun 2017 ini saham Bank Muamalat rencananya akan dibeli oleh PT. Minna Padi Investama Sekuritas sebesar $51 \%$. Fenomena berikutnya juga diberitakan bahwa pemilik Mayapada Group, (5)Tahir menawarkan Rp 5 triliun untuk membeli 100\% saham Bank Muamalat Indonesia Tbk. Tawaran itu mendapat resistensi dari pemegang saham. Yang kemudian para pemegang saham Bank Muamalat Indonesia, Tbk menanggapi hal tersebut 
dengan resistensi [24] maka berdasarkan fenomena tersebut penelitian ini akan melihat betulkah Bank Mualamat Indonesia mengalami kendala kesehatan.

Menilai kesehatan bank dapat dilihat dari berbagai aspek. Penilaian ini bertujuan akan memantau apakah bank tersebut dalam keadaan yang sangat sehat, sehat, cuku sehat, kurang sehat atau bahkan yang lebih ekstrim adalah kondisi tidak sehat. Bagi bank yang sehat harus berupaya mempertahankan kesehatannya namun bagi bank yang tidak sehat harus segera mengatasi penyakitnya. Pemerintah melalui Bank Indonesia sudah memberikan standar yang antara lain semua bank diwajibkan membuat laporan yang akuntabel dan transparan baik yang bersifat rutin atau berkala tentang seluruh aktivitasnya dalam suatu periode tertentu. Bank Indonesia mulai efektif pada Januari 2012 dengen menggunakan laporan keuangan per Desember 2011 sudah juga melakukan perubahan, saat ini cara pengukuran kesehatan bank menggunakan metode RGEC (Risk Profile, Good Corporate Governance, Earnings And Capital).

\section{Kajian Pustaka}

Bank Indonesia telah mengeluarkan peraturan yang tercantum pada PBI N0. 13/1/PBI/2011 tentang sistem penilaian tingkat kesehatan bank. Manajemen yang berkualitas merupakan kunci penting dalam menjaga kesehatan bank. Manajemen yang berkualitas baik dapat dilihat dari penerapan manajemen risiko yang baik dan GCG pada bank tersebut. Faktor rentabilitas dan juga permodalan hanya merupakan dampak akibat strategi yang ditetapkan dan dilakukan oleh pihak manajemen(13)(14)(15)(16)(17).

\subsection{Risiko Profil (Risk Profile)}

Risiko Profil merupakan pengukuran terhadap risiko dari dalam serta kualitas pengelolaan manajemen risiko untuk masing - masing risiko dalam setiap aktivitas operasional bank.

\subsection{Risiko Kredit}

Risiko kredit adalah risiko yang terjadi akibat kegagalan pihak nasabah ataupun pihak lain dalam pemenuhan kewajiban yang sesuai dengan perjanjian yang disepakati antara nasabah atau pihak lain kepada bank. Rasio yang digunakan untuk mengukur risiko ini adalah menggunakan risiko penyaluran dana yang bermasalah atau lazim disebut NPF (Non Performing Financing).

\subsection{Penilaian GCG (Good Corporate Governance)}

GGC atau Good Corporate Governance merupakan monitoring pada kinerja menemejemn serta melihat akuntabilitas pihak manajemen terhadap pemegang kepentingan (stakeholder) mengacu berdasarkan pada standard dan peraturan (Nasution dan Setiawan : 2007)(18).

\subsection{Earnings (Rentabilitas)}


Tujuan dari rentabilitas adalah untuk melihat kemampuan sebuah bank dalam menghasilkan laba selama periode tertentu, selain itu juga dapat digunakan untuk melihat dan mengukur seberapa efektif pihak manajemen dalam melakukan operasional bank (11), pada penelitian ini rentabilitas akan menggunakan perhitungan rasio Return On Assets (ROA), Return On Equity (ROE), dan Net Operating Margin (NOM).

\subsection{Beban Operasional terhadap Pendapatan Operasional (BOPO)}

(19)Beban Operasional terhadap Pendapatan Operasional adalah rasio efisiensi yang digunakan untuk melihat dan mengukur kemampuan pihak manajemen bank dalam pengendalian biaya operasional terhadap pendapatan operasional. Biaya operasi adalah biaya biaya yang dikeluarkan oleh bank dalam menjalankan operasional utamanya. Sedangkan pendapatan operasi merupakan pendapatan utama bank yaitu pendapatan yang diperoleh dari penyaluran dana dan pendapatan operasi lainnya (Riyadi, 2006).

\subsection{Capital (Permodalan)}

Faktor permodalan merupakan evaluasi dari kecukupan modal dan juga kecukupan pengelolaannya. Permodalan memiliki beberapa indicator antara lain rasio kecukupan modal yang digunakan untuk melihat dan mengantisipasi kerugian yang terjadi sesuai profil risiko.

\section{Metodologi Penelitian}

\subsection{Kerangka Pemikiran}

Untuk mengukur kinerja Bank Muamalat Indonesia, penulis menganalisis faktor keuangan dengan metode yang sudah ditetapkan oleh (11)Bank Indonesia dalam Peraturan Bank Indonesia No.13/1/PBI/2011 dan Surat Edaran Otoritas Jasa Keuangan No. 10/SEOJK.03/2014 tentang penilaian tingkat kesehatan Bank Umum Syariah dan Unit Usaha Syariah. Faktor keuangan yang digunakan yaitu: Risk Profile, Good Corporate Governance, Earnings, dan Capital (RGEC)(20). Berdasarkan uraian yang telah dikemukakan sebelumnya, sebagai dasar untuk mengarahkan pemikiran dalam penelitian ini untuk tingkat kesehatan Bank Umum Syariah.

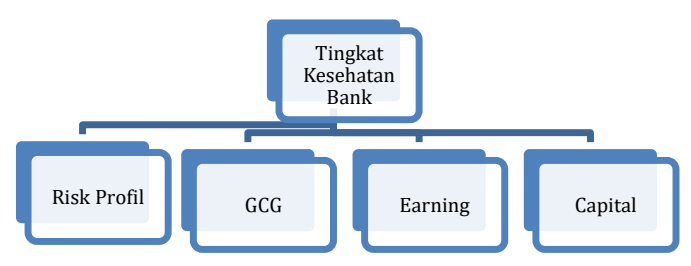

Gambar Rerangka Pemikiran 


\subsection{Definisi dan Operasionalisasi Variabel Profil Risiko}

(21) Profil Risiko diukur dengan emnggunakan rasio pembiayaan bermasalah.

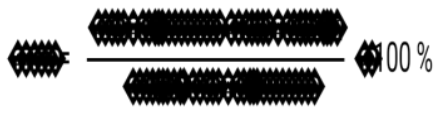

Tabel Kriteria Penilaian NPF

\begin{tabular}{|c|c|c|}
\hline \multicolumn{3}{|c|}{ KRITERIA PENILAIAN PERINGKAT } \\
\hline Peringkat & Keterangan & Kriteria \\
\hline 1 & Sangat Sehat & NPF $\leq 7 \%$ \\
\hline 2 & Sehat & $7 \% \leq \mathrm{NPF} \leq 10 \%$ \\
\hline 3 & Cukup Sehat & $10 \% \leq \mathrm{NPF} \leq 13 \%$ \\
\hline 4 & Kurang Sehat & $13 \% \leq \mathrm{NPF} \leq 16 \%$ \\
\hline 5 & Tidak Sehat & NPF $\geq 16 \%$ \\
\hline
\end{tabular}

Pengukuran risiko likuiditas dilihat dari pengukuran rasio penempaatan atau penyaluran dana dengan mengukur rasio FRD (Financing to Deposit Ratio).

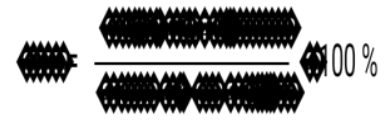

Tabel Kriteria Penilaian FDR 


\begin{tabular}{|c|c|c|}
\hline \multicolumn{3}{|c|}{ KRITERIA PENILAIAN PERINGKAT } \\
\hline Peringkat & Keterangan & Kriteria \\
\hline 1 & Sangat Sehat & $50 \%<$ FDR $\leq 75 \%$ \\
\hline 2 & Sehat & $75 \%<$ FDR $\leq 85 \%$ \\
\hline 3 & Cukup Sehat & $85 \%<$ FDR $\leq 100 \%$ \\
\hline 4 & Kurang Sehat & $100 \%<$ FDR $\leq 120 \%$ \\
\hline 5 & Tidak Sehat & FDR $\geq 120 \%$ \\
\hline
\end{tabular}

\section{Good Corporate Governance}

(22)GCG (Good Corporate Governance) dalam penelitian ini diukur dengan menggunakan nilai komposit self assessment yang dipublikasikan oleh Bank Muamalat Indonesia pada Laporan GCG.

Tabel Kriteria Penilaian GCG

\begin{tabular}{|c|c|c|}
\hline \multicolumn{3}{|c|}{ KRITERIA PENILAIAN PERINGKAT } \\
\hline Peringkat & Keterangan & Kriteria \\
\hline 1 & Sangat Sehat & NK $\leq 1,5$ \\
\hline 2 & Sehat & $1,5 \leq \mathrm{NK} \leq 2,5$ \\
\hline 3 & Cukup Sehat & $2,5 \leq \mathrm{NK} \leq 3,5$ \\
\hline 4 & Kurang Sehat & $3,5 \leq \mathrm{NK} \leq 4,5$ \\
\hline 5 & Tidak Sehat & $4,5 \leq \mathrm{NK} \leq 5$ \\
\hline
\end{tabular}

\section{Earnings}

NOM dengan menggunakan rumus:

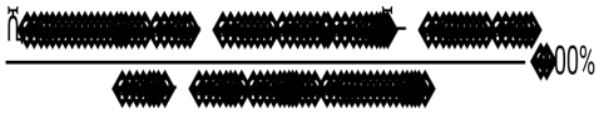


Tabel Kriteria Penilaian NOM

\begin{tabular}{|c|c|c|}
\hline \multicolumn{3}{|c|}{ KRITERIA PENILAIAN PERINGKAT } \\
\hline Peringkat & Keterangan & Kriteria \\
\hline 1 & Sangat Sehat & NOM $>5 \%$ \\
\hline 2 & Sehat & $2,01 \%<\mathrm{NOM} \leq 5 \%$ \\
\hline 3 & Cukup Sehat & $1,5 \%<\mathrm{NOM} \leq 2 \%$ \\
\hline 4 & Kurang Sehat & $0 \%<\mathrm{NOM} \leq 1,49 \%$ \\
\hline 5 & Tidak Sehat & NOM $<0 \%$ \\
\hline
\end{tabular}

BOPO dengan menggunakan rumus:

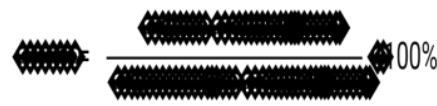

Tabel Kriteria Penilaian BOPO

\begin{tabular}{|c|c|c|}
\hline \multicolumn{3}{|c|}{ KRITERIA PENILAIAN PERINGKAT } \\
\hline Peringkat & Keterangan & Kriteria \\
\hline 1 & Sangat Sehat & REO $\leq 83 \%$ \\
\hline 2 & Sehat & $83 \%<\mathrm{REO} \leq 85 \%$ \\
\hline 3 & Cukup Sehat & $85 \%<\mathrm{REO} \leq 87 \%$ \\
\hline 4 & Kurang Sehat & $87 \%<\mathrm{REO} \leq 89 \%$ \\
\hline 5 & Tidak Sehat & REO $>89 \%$ \\
\hline
\end{tabular}

\section{Capital}

Capital atau Permodalan yaitu metode penilaian bank berdasarkan permodalan yang dimiliki bank.

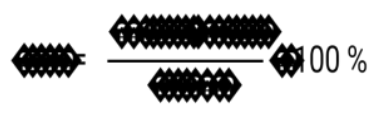

Tabel Kriteria Penilaian Permodalan 


\begin{tabular}{|c|c|c|}
\hline \multicolumn{3}{|c|}{ KRITERIA PENILAIAN PERINGKAT } \\
\hline Peringkat & Keterangan & Kriteria \\
\hline 1 & Sangat Sehat & KPMM $\geq 12 \%$ \\
\hline 2 & Sehat & $9 \% \leq \mathrm{KPMM}<12 \%$ \\
\hline 3 & Cukup Sehat & $8 \% \leq \mathrm{KPMM}<9 \%$ \\
\hline 4 & Kurang Sehat & $6 \% \leq \mathrm{KPMM}<8 \%$ \\
\hline 5 & Tidak Sehat & KPMM $\geq 6 \%$ \\
\hline
\end{tabular}

\section{Kesimpulan Penelitian}

1. Hasil penelitian Risk Profile (Profil Risiko) Bank Mualamat Indonesia(23), Tbk periode tahun 2015-2017 indikator yaitu faktor risiko kredit yang menggunakan rasio NPF (Net Performing Financing) dengan hasil sebagai berikut:

Tabel Perhitungan Rasio NPF Bank Muamalat Indonesia Tahun 2015 - 2017

\begin{tabular}{|c|c|c|}
\hline \multicolumn{3}{|c|}{ NPF (Non Performing Financing) } \\
\hline Tahun & Rasio (\%) & Kriteria \\
\hline 2015 & 4,33 & Sangat Baik \\
\hline 2016 & 4,20 & Sangat Baik \\
\hline 2017 & 2,75 & Sangat Baik \\
\hline
\end{tabular}

Penelitian Risk Profile (Profil Risiko) Bank Mualamat Indonesia, Tbk periode tahun 2015-2017 indikator yaitu faktor risiko kredit yang menggunakan rasio FDR (Financing to Deposit Ratio) dengan hasil penelitian adalah sebagai berikut:

Tabel Perhitungan Rasio FDR Bank Muamalat Indonesia Tahun 2015 - 2017

\begin{tabular}{|c|c|c|}
\hline \multicolumn{3}{|c|}{ FDR (Financing to Deposit Ratio) } \\
\hline Tahun & Rasio (\%) & Kriteria \\
\hline 2015 & 90,30 & Cukup Baik \\
\hline 2016 & 97,30 & Cukup Baik \\
\hline 2017 & 84,41 & Baik \\
\hline
\end{tabular}

2. Hasil penelitian GCG (Good Corporate Governance) Bank Muamalat Indonesia, Tbk periode tahun 2015-2017 dengan metode Self Assessment oleh Bank Muamalat 
Indonesia, Tbk diperoleh nilai komposit GCG (Good Corporate Governance) sebagai berikut:

Tabel Perhitungan GCG Bank Muamalat Indonesia Tahun 2015 - 2017

\begin{tabular}{|c|c|c|}
\hline \multicolumn{3}{|c|}{ GCG (Good Corporate Governance) } \\
\hline $\begin{array}{c}\text { Tahu } \\
\text { n }\end{array}$ & Nilai Komposit & Kriteria \\
\hline 2015 & 3 & Cukup Baik \\
\hline 2016 & 2 & Baik \\
\hline 2017 & 2 & Baik \\
\hline
\end{tabular}

Nilai komposit Bank Muamalat Indonesia yang tertera pada penjelasan tersebut diatas memperlihatkan bahwa pelaksanaan prinsip = prinsip GCG pada Bank Muamalat Indonesia di tahun 2015 - 2017 dapat dinyatakan telah terlaksana dengan baik.

3. Hasil penelitian Earnings (Rentabilitas) Bank Muamalat Indonesia, Tbk periode tahun 2015-2017 dengan menggunakan rasio ROA (Return On Assets) dengan hasil sebagai berikut:

Tabel Perhitungan Rasio ROA Bank Muamalat Indonesia Tahun 2015 - 2017

\begin{tabular}{|c|c|c|}
\hline \multicolumn{3}{|c|}{ ROA (Return On Asset) } \\
\hline $\begin{array}{c}\text { Tahu } \\
\text { n }\end{array}$ & Nilai Komposit & Kriteria \\
\hline 2015 & 0,19 & Kurang Baik \\
\hline 2016 & 0,21 & Kurang Baik \\
\hline 2017 & 0,10 & Kurang Baik \\
\hline
\end{tabular}

Hasil penelitian Earnings (Rentabilitas) Bank Muamalat Indonesia, Tbk periode tahun 2015-2017 dengan menggunakan rasio ROE (Return On Equity) dengan hasil sebagai berikut:

Tabel Perhitungan Rasio ROE Bank Muamalat Indonesia Tahun 2015 - 2017

\begin{tabular}{|c|c|c|}
\hline \multicolumn{3}{|c|}{ ROE (Return On Equity) } \\
\hline Tahun & Rasio (\%) & Kriteria \\
\hline 2015 & 2,11 & Kurang Baik \\
\hline 2016 & 2,22 & Kurang Baik \\
\hline 2017 & 0,47 & Kurang Baik \\
\hline
\end{tabular}

Hasil penelitian Rentabilitas Bank Muamalat Indonesia, Tbk periode tahun 20152017 dengan menggunakan rasio NOM (Net Operating Margin) dengan hasil sebagai berikut: 
Tabel Perhitungan Rasio NOM Bank Muamalat Indonesia Tahun 2015 - 2017

\begin{tabular}{|c|c|c|}
\hline \multicolumn{3}{|c|}{ NOM (Net Operating Margin) } \\
\hline Tahun & Rasio (\%) & Kriteria \\
\hline 2015 & 0,27 & Kurang Baik \\
\hline 2016 & 0,30 & Kurang Baik \\
\hline 2017 & 0,21 & Kurang Baik \\
\hline
\end{tabular}

Hasil penelitian Rentabilitas Bank Muamalat Indonesia, Tbk periode tahun 20152017 dengan menggunakan rasio BOPO dengan hasil sebagai berikut:

Tabel Perhitungan Rasio BOPO Bank Muamalat Indonesia Tahun 2015 - 2017

\begin{tabular}{|c|c|c|}
\hline \multicolumn{3}{|c|}{ BOPO } \\
\hline Tahun & Rasio $(\%)$ & Kriteria \\
\hline 2015 & 97,41 & Tidak Baik \\
\hline 2016 & 97,32 & Tidak Baik \\
\hline 2017 & 97,68 & Tidak Baik \\
\hline
\end{tabular}

4. Hasil penelitian Permodalan Bank Muamalat Indonesia, Tbk periode 2015-2017 dengan hasil sebagai berikut:

Tabel Perhitungan Rasio CAR Bank Muamalat Indonesia Tahun 2015 2017

\begin{tabular}{|c|c|c|}
\hline \multicolumn{3}{|c|}{ CAR } \\
\hline $\begin{array}{c}\text { Tahu } \\
\mathbf{n}\end{array}$ & Rasio (\%) & Kriteria \\
\hline 2015 & 12,00 & Sangat Baik \\
\hline 2016 & 12,74 & Sangat Baik \\
\hline 2017 & 13,62 & Sangat Baik \\
\hline
\end{tabular}

5. Hasil penelitian tingkat kesehatan Bank Muamalat Indonesia, Tbk dilihat dari aspek RGEC (Risk Profile, Good Corporate Governance, Earnings, Capital) periode tahun 2015-2017 menempati peringkat cukup sehat. Sehingga Bank Muamalat Indonesia, Tbk dinilai cukup mampu menghadapi pengaruh negatif yang 
signifikan dari perubahan kondisi bisnis dan faktor eksternal maupun internal lainnya.

Tabel Penetapan Peringkat Bank Muamalat Indonesia Berdasarkan Metode RGE pada Tahun 2015-2017

\begin{tabular}{|c|c|c|c|c|c|c|c|c|c|c|c|}
\hline \multirow{2}{*}{ Tahun } & \multirow{2}{*}{$\begin{array}{l}\text { Kompone } \\
\text { n Faktor }\end{array}$} & \multirow{2}{*}{ Rasio } & \multirow{2}{*}{ Nilai } & \multicolumn{5}{|c|}{ Peringkat } & \multirow{2}{*}{ Kriteria } & \multirow{2}{*}{$\begin{array}{c}\text { Keteranga } \\
\mathbf{n}\end{array}$} & \multirow{2}{*}{$\begin{array}{c}\text { Peringka } \\
\mathbf{t} \\
\text { Komposi } \\
\mathbf{t} \\
\end{array}$} \\
\hline & & & & 1 & 2 & 3 & 4 & 5 & & & \\
\hline \multirow{9}{*}{2015} & \multirow{2}{*}{$\begin{array}{c}\text { Risk } \\
\text { Profile }\end{array}$} & NPF & $4,20 \%$ & $\mathrm{~V}$ & & & & & $\begin{array}{l}\text { Sangat } \\
\text { Baik }\end{array}$ & \multirow{2}{*}{ Sangat Baik } & \multirow{9}{*}{$\begin{array}{l}\text { Cukup } \\
\text { Baik }\end{array}$} \\
\hline & & FDR & $90,30 \%$ & & & V & & & $\begin{array}{l}\text { Cukup } \\
\text { Baik }\end{array}$ & & \\
\hline & GCG & GCG & & & & $\sqrt{ }$ & & & $\begin{array}{c}\text { Sangat } \\
\text { Baik }\end{array}$ & Sangat Baik & \\
\hline & \multirow{4}{*}{ Earnings } & ROA & $0,19 \%$ & & & & V & & $\begin{array}{c}\text { Kurang } \\
\text { Baik }\end{array}$ & \multirow{4}{*}{ Kurang Baik } & \\
\hline & & ROE & $2,11 \%$ & & & & V & & $\begin{array}{c}\text { Kurang } \\
\text { Baik }\end{array}$ & & \\
\hline & & NOM & $0,27 \%$ & & & & V & & $\begin{array}{c}\text { Kurang } \\
\text { Baik }\end{array}$ & & \\
\hline & & BOPO & $97,41 \%$ & & & & & V & $\begin{array}{l}\text { Tidak } \\
\text { Baik }\end{array}$ & & \\
\hline & Capital & CAR & $12,00 \%$ & V & & & & & $\begin{array}{l}\text { Sangat } \\
\text { Baik }\end{array}$ & Sangat Baik & \\
\hline & \multicolumn{2}{|c|}{ Nilai } & 40 & 10 & & 6 & 6 & 1 & \multicolumn{2}{|c|}{57,5} & \\
\hline \multirow{8}{*}{2016} & \multirow{2}{*}{$\begin{array}{c}\text { Risk } \\
\text { Profile }\end{array}$} & NPF & $4,33 \%$ & V & & & & & $\begin{array}{l}\text { Sangat } \\
\text { Baik }\end{array}$ & \multirow{2}{*}{ Sangat Baik } & \multirow{8}{*}{$\begin{array}{l}\text { Cukup } \\
\text { Baik }\end{array}$} \\
\hline & & FDR & $97,30 \%$ & & & V & & & $\begin{array}{l}\text { Cukup } \\
\text { Baik }\end{array}$ & & \\
\hline & GCG & GCG & & & $\sqrt{ }$ & & & & & Sangat Baik & \\
\hline & \multirow{4}{*}{ Earnings } & ROA & $0,21 \%$ & & & & V & & $\begin{array}{c}\text { Kurang } \\
\text { Baik }\end{array}$ & \multirow{4}{*}{ Kurang Baik } & \\
\hline & & ROE & $2,22 \%$ & & & & V & & $\begin{array}{c}\text { Kurang } \\
\text { Baik }\end{array}$ & & \\
\hline & & NOM & $0,30 \%$ & & & & V & & $\begin{array}{c}\text { Kurang } \\
\text { Baik }\end{array}$ & & \\
\hline & & BOPO & $97,32 \%$ & & & & & V & $\begin{array}{l}\text { Tidak } \\
\text { Baik }\end{array}$ & & \\
\hline & Capital & CAR & $12,74 \%$ & V & & & & & $\begin{array}{c}\text { Sangat } \\
\text { Baik }\end{array}$ & Sangat Baik & \\
\hline
\end{tabular}




\begin{tabular}{|c|c|c|c|c|c|c|c|c|c|c|c|}
\hline & \multicolumn{2}{|c|}{ Nilai } & 40 & 10 & 4 & 3 & 6 & 1 & \multicolumn{2}{|c|}{60} & \\
\hline \multirow{9}{*}{2017} & \multirow{2}{*}{$\begin{array}{c}\text { Risk } \\
\text { Profile }\end{array}$} & NPF & $2,75 \%$ & $V$ & & & & & $\begin{array}{c}\text { Sangat } \\
\text { Baik }\end{array}$ & \multirow{2}{*}{ Sangat Baik } & \multirow{9}{*}{$\begin{array}{c}\text { Cukup } \\
\text { Baik }\end{array}$} \\
\hline & & FDR & $84,41 \%$ & & V & & & & $\begin{array}{l}\text { Cukup } \\
\text { Baik }\end{array}$ & & \\
\hline & GCG & GCG & & & V & & & & & Sangat Baik & \\
\hline & \multirow{4}{*}{ Earnings } & ROA & $0,10 \%$ & & & & V & & $\begin{array}{c}\text { Kurang } \\
\text { Baik }\end{array}$ & \multirow{4}{*}{ Kurang Baik } & \\
\hline & & ROE & $0,47 \%$ & & & & V & & $\begin{array}{c}\text { Kurang } \\
\text { Baik }\end{array}$ & & \\
\hline & & NOM & $0,21 \%$ & & & & V & & $\begin{array}{c}\text { Kurang } \\
\text { Baik }\end{array}$ & & \\
\hline & & BOPO & $97,68 \%$ & & & & & V & $\begin{array}{c}\text { Tidak } \\
\text { Baik }\end{array}$ & & \\
\hline & Capital & CAR & $13,62 \%$ & $V$ & & & & & $\begin{array}{c}\text { Sangat } \\
\text { Baik }\end{array}$ & Sangat Baik & \\
\hline & \multicolumn{2}{|c|}{ Nilai } & 40 & 10 & 8 & & 6 & 1 & \multicolumn{2}{|c|}{62,5} & \\
\hline
\end{tabular}

\section{Saran Penelitian}

1. Penelitian faktor Risk Profile hanya menggunakan 2 (dua) indikator dari yang sebenarnya adalah 8 (delapan) indikator yaitu risiko kredit dan risiko likuiditas. Sedangkan 6 (enam) risiko lainnya yaitu risiko pasar, risiko hukum, risiko operasional, risiko strategik, risiko kepatuhan, dan risiko reputasi. Untuk penelitian selanjutnya dapat diharapkan lebih banyak menggunakan indikator untuk menilai faktor Risk Profile.

2. Untuk rasio Earnings (Rentabilitas) sebaiknya Bank Muamalat Indonesia, Tbk memperbaiki hal dalam segala aspek. Karena sebagai pelopor Bank Syariah pertama di indonesia seharusnya Bank Muamalat Indonesia, Tbk dapat menunjukkan kekuatannya di berbagai aspek termasuk dalam aspek rentabilitas ini. Bank Muamalat Indonesia, Tbk harus meminimalisis beban operasional perusahaan sehingga bank semakin efisien.

3. Untuk penelitian ini hanya menggunakan sampel dari tahun 2015-2017. Untuk kedepannya peneliti berikutnya dapat menambahkan tahun dan sampel penelitian agar diharapkan dapat memberikan hasil yang lebih baik.

4. Sebagai pelopor Bank Syariah pertama di Indonesia, sebaiknya Bank Muamalat Indonesia, Tbk dapat terus meningkatkan kesehatan bank pada tahun-tahun selanjutnya. Karena tingkat kesehatan bank yang baik juga akan meningkatkan kepercayaan stakeholder terutama nasabahnya.

5. Untuk masyarakat, investor, dan calon investor seharusnya tidak perlu khawatir terhadap keadaan Bank Muamalat Indonesia, Tbk karena hasil dari penelitian ini dapat sebagai acuan bahwa Bank Muamalat Indonesia, Tbk dalam keadaan baik-baik saja. 


\section{Referensi}

1. Kasmir. Bank dan Lembaga Keuangan Lainnya. Edisi Revisi 2014 Jakarta: PT. Raja Grafindo Persada. 2014;

2. POJK. Nomor 8/POJK.3/2014. Perihal Penilaian Tingkat Kesehatan Bank.Jakarta: OJK.

3. Republika. 51 Persen Saham Bank Muamalat Resmi Dibeli Minna Padi. 2017; Available from: republika.co.id/berita/ekonomi/syariahekonomi/17/09/28/owzh0n383-51-persen-saham-bank-muamalat-resmi-dibeli-minnapadi

4. Budi Santoso T dan ST. Bank dan Lembaga Keuangan Lain. Edisi 2. Jakarta: Salemba Empat. 2006.

5. Klikkabar. Tahir Tawar Beli Saham Muamalat. 2018; Available from: klikkabar.com/2018/09/27/tahir-tawar-beli-saham-muamalat/

6. Fitriana N, Rosyid A, Fakhrina A. Analisis Perbandingan Tingkat Kesehatan Bank Syariah Dan Konvensional Dengan Menggunakan Metode Rgec ( Risk Profile, Good Corporate Governance , Earnings , Dan Capital ). Fak Ekon dan Bisnis. 2015;17(2):112.

7. Mandasari J. Analisis Kinerja Keuangan Dengan Pendekatan Metode RGEC Pada Bank BUMN Periode 2012-2013. E-Jurnal Ilmu Administrasi Bisnis. 2015;

8. Indonesia B. Peraturan Bank Indonesia No. 13/23/PBI/2011 Perihal. 2011;

9. Surat Edaran Bank Indonesia No. 13/24/DPNP Perihal Penilaian Tingkat Kesehatan Bank Umum. Jakarta: Bank Indonesia.

10. Bank Indonesia. Penilaian Tingkat Kesehatan Bank Umum. Jakarta: Bank Indonesia.

11. Indonesia B. Peraturan Bank Indonesia No. 13/1/PBI/2011 Perihal Penilaian tingkat Kesehatan Bank Umum. Jakarta: Bank Indonesia. 2011;

12. Husein AR. Adln - perpustakaan universitas airlangga analisis perbandingan tingkat kesehatan bank dengan menggunakan pendekatan camels dan rgec. 2016;

13. Dewi M. Analisis Tingkat Kesehatan Bank Dengan Menggunakan Pendekatan Rgec (Risk Profile, Good Corporate Governance, Earnings, Capital) (Studi Pada Pt. Bank Rakyat Indonesia, Tbk Periode 2013-2017). Niagawan. 2014;7(3):67.

14. Oktaviani LMF dan UK. Analisis Tingkat Kesehatan Bank Umum Syariah dan Unit Usaha Syariah Dengan Metode CAMELS dan RGEC. UIN Maulana Malik Ibrahim Malang. J Chem Inf Model. 2015;53(9):1689-99.

15. AJI PERMANA B. Analisis Tingkat Kesehatan Bank Berdasarkan Metode CAMELS dan Metode RGEC. J Akunt Unesa. 2013;1(1):1-21.

16. Gede L, Artini S. ANALISIS TINGKAT KESEHATAN BANK ( PENDEKATAN RGEC ) PADA PT . BANK DANAMON INDONESIA. 2016;5(6):3849-78.

17. Alawiyah T. Metode RGEC Pada Bank Umum BUMN Yang Terdaftar Di Bursa Efek Indonesia Tahun 2012 - 2014. Pendidik dan Ekon. 2016;5(3):114-23.

18. Nasution M, Setiawan D. Pengaruh Good Corporate Governance Terhadap. J Ekon Mod. 2008;4:67-77.

19. Indonesia B. Booklet Perbankan Indonesia 2016. Jakarta: Bank Indonesia.

20. Hendrayana P, Yasa G. Pengaruh Komponen Rgec Pada Perubahan Harga Saham Perusahaan Perbankan Di Bursa Efek Indonesia. E-Jurnal Akunt. 2015;11(1):74-89.

21. Rahmi CL. Pengaruh Risiko Kredit, Risiko Likuiditas Dan Risiko Tingkat Bunga Terhadap Profitabilitas (Studi Empiris pada Perusahaan Perbankan Terdaftar di Bursa 
Efek Indonesia). Artik Srkipsi [Internet]. 2014;1-22. Available from:

http://ejournal.unp.ac.id/students/index.php/akt/article/view/1537

22. Hamdani. Good Corporate Governance Tinjauan Etika dalam Praktik Bisnis. Jakarta: Penerbit Mitra Wacana Media. 2016;

23. Bank Muamalat Indonesia. 